\title{
MIRADAS Y TENSIONES EN TORNO A LA NACIONALIDAD DE PERSONAS MIGRANTES EN LA ATENCIÓN DE SALUD EN JOSÉ C. PAZ
}

PAULA V. Estrella

Dra. en Antropología

Universidad Nacional de José Clemente Paz (UNPAZ) pvestrella@gmail.com·https://orcid.org/0000-0001-9137-9332

Resumen. En Argentina, los procesos migratorios han tenido diferentes niveles de legitimación de acuerdo con los países de origen de las personas migrantes, así como por medio de discursos políticos oficiales y académicos, que permearon a la opinión pública a través de los medios de comunicación. Las miradas que se fueron construyendo históricamente en torno a los «otros» migrantes se reproducen y actualizan en diversos ámbitos. Abordamos las miradas y tensiones vinculadas a la nacionalidad de migrantes expresadas por el personal de salud y por las mujeres migrantes usuarias de centros de atención primaria de la salud (CAPS) en el Municipio de José C. Paz, Provincia de Buenos Aires, Argentina, para conocer cómo conciben sus interacciones y la atención de salud. A partir de ello buscamos desentrañar la lógica (o lógicas) por la cual se marcan o desmarcan «diferencias» de nacionalidad en distintos contextos. Para ello efectuamos un estudio exploratorio de corte transversal desde un enfoque cualitativo. Integramos el análisis de fuentes secundarias con la producción de fuentes primarias (a partir de observación participante y 
entrevistas semiestructuradas). En total realizamos 23 entrevistas, 12 a mujeres usuarias migrantes y 11 a trabajadores/as de tres centros de atención primaria de la salud (CAPS), durante febrero y marzo de 2019.

Palabras Clave: migraciones; mujeres usuarias migrantes; atención de la salud; tensiones; prejuicios.

Perspectives and tensions Regarding the Nationality of MigRants in Health CARe in José C. PaZ

ABSTRACT. In Argentina, migratory processes have had different levels of legitimacy depending on the migrants' countries of origin and on official and academic political discourses, which permeated public opinion through the media. The perspectives that were historically built around the "other" migrants have been reproduced and updated in various areas. We address the perspectives and tensions regarding the nationality of migrants expressed by health personnel and female migrant users of Primary Health Care Centers (CAPS) in the Municipality of José C. Paz, Province of Buenos Aires, Argentina to learn how they perceive their interactions and health care. From this, we seek to unravel the logic/s by which "differences" of nationality are marked or unmarked in different contexts. To do so, we carry out an exploratory cross-sectional and qualitative study that integrates the analysis of secondary sources with the production of primary sources (from participant observation and semi-structured interviews). In total, we conducted 23 interviews, 12 with migrant women users and 11 with workers from three Primary Health Care Centers (CAPS), during the months of February and March 2019.

KEYWORDS: migrations; migrant female users; health care; tensions; prejudices. 


\section{Introducción}

En Argentina, la cuestión migratoria ha estado permeada por discursos dominantes sobre la descendencia de los barcos. Se ha vinculado la conformación del Estado nacional con las primeras oleadas de inmigrantes europeos, sin embargo, previamente, el territorio estaba poblado por pueblos originarios, que fueron invisibilizados y destinatarios de campañas militares de exterminio dirigidas principalmente por el gral. Julio A. Roca. Desde fines del siglo xIx y principios del siglo xx, las migraciones de «europeos» se presentaron «justificadas» y promovidas por causas económico-laborales y con fines de «modernización» del país. Tanto italianos como españoles (entre otros) vinieron motivados por la búsqueda de trabajo y/o escapando de las guerras, así como por las expectativas de ascenso social. Sin embargo, este caudal migratorio se interrumpió hacia fines de los años cuarenta. En este contexto, apareció un flujo permanente y sostenido de migrantes latinoamericanos, especialmente de países limítrofes, que nutrió las necesidades temporales de trabajo y se complementaba con los movimientos migratorios del interior del país (Devoto, 2003, en Castiglione, 2004).

Durante los años noventa, en pleno neoliberalismo, se despertó la esperanza de miles de personas que vinieron desde países cercanos pensando que su esfuerzo e incluso su sobreesfuerzo tenían como consecución lógica el envío de remesas (Castiglione, 2004), lógica que se vio alterada por la crisis económica pre-y pos-2001. Desde distintos ámbitos del Estado, sindicatos y medios de comunicación se delinearon discursos que adjudicaron a los inmigrantes la responsabilidad por los problemas sociales y económicos (Pratto, 2016).

Es por ello que los diversos procesos migratorios de acuerdo con los países de orígenes encontraron diferentes niveles de legitimación, tanto por los discursos políticos oficiales y académicos como por la opinión pública a través de los medios de comunicación. En este sentido, a diferencia de los inmigrantes europeos de mitad de siglo xix y principios del siglo $\mathrm{xx}$, los de fines del siglo xx y principios del xxi presentaron orígenes colindantes y fueron desde entonces cuestionados. 
Estos desplazamientos, a pesar de implicar numerosos obstáculos y padecimientos, fueron prometedores en tanto que crearon expectativas de un trabajo y vida mejores, así como de facilidades en el acceso a la atención de la salud, a la educación y a la vivienda, entre otros. A ello se sumó que la legislación ha permitido un libre acceso al país a través de la Ley 25.871, de Migraciones, de la República Argentina.

Los análisis sociológicos actuales sobre migraciones y trabajo plantean, por un lado, que la discriminación y xenofobia provocarían estrategias de negación y disimulo por parte de los propios discriminados (Margulis y Urresti, 1998, en Trpin y Vargas, 2004), y, por otro, que la inserción de migrantes limítrofes en Buenos Aires se produce como inserción selectiva en determinados segmentos del mercado laboral, donde los limítrofes ocuparían posiciones marcadamente distintas que los trabajadores nativos, en empleos mal pagados, inestables y con pocas posibilidades de ascenso (Maguid, 1997, en Trpin y Vargas, 2004). Sin embargo, investigaciones etnográficas en torno a migrantes y trabajo (Trpin, 2004; Vargas, 2005) muestran que los migrantes limítrofes no ocultan ni niegan sus nacionalidades y ocupan en algunos ámbitos laborales diversos rangos de las «categorías» disponibles. Incluso las nacionalidades de migrantes limítrofes, en lugar de ser un estigma, se constituyen como un recurso que incrementa sus posibilidades de conseguir empleo (Trpin y Vargas, 2004).

En este sentido, las oportunidades y posibilidades laborales han sido señaladas como los motivos más frecuentes de los desplazamientos migratorios. A ello se han sumado expectativas/ perspectivas de un avance/progreso que los colocaría en otra posición socioeconómica a corto o mediano plazo. A pesar de la diversidad de causas posibles — políticas, económicas, humanitarias, medioambientales-, las migraciones afectan los procesos de salud-enfermedad-atención (PSEA) ${ }^{1}$ de las personas y/o grupos que migran.

I El término PSEA se utiliza para definir la salud y enfermedad como parte de un mismo proceso que es dinámico y que no puede disociarse de la atención, pues ella lo condiciona. A su vez, la atención de los procesos de salud y enfermedad no necesariamente se da a través de la biomedicina, sino que existen otros modelos de atención que las personas utilizan para prevenir, dar tratamiento, controlar, aliviar y/o curar un padecimiento determinado (Menéndez, 2004). 
A partir de las trayectorias de las mujeres migrantes usuarias de los centros de atención primaria de la salud (CAPS) de José C. Paz, pudimos observar (a pesar de la diversidad de situaciones) las posibilidades que les brindó contar con algún allegado, familiar o compadre/comadre, o amigo, que las acogió o alojó para «adaptarse», «aprender a manejarse», solventarse económicamente, o asistir a instituciones sanitarias para recibir atención, entre otras ayudas primordiales. Además de valorar los logros alcanzados relacionados con la migración, como tener su propia familia, su propia casa, poder estudiar o tener acceso a la atención de salud, la mayoría mencionó no haber sufrido situaciones de discriminación y/o maltrato hacia ellas ni hacia personas migrantes familiares o cercanas. Esta situación nos llamó la atención ya que contrastaba con los relatos de promotoras de salud que denunciaban la xenofobia y/o racismo hacia paraguayos y otros migrantes en esos barrios y con parte del personal de salud que expresaba su desacuerdo con las políticas migratorias y la permisibilidad y «facilidades» que se les daban a los «extranjeros» de países limítrofes, como dejarlos entrar sin pedirles «nada» o que tengan salud y educación «gratis».

Otro aspecto relevante en torno a los procesos migratorios en contextos locales, que relevamos a partir de nuestro trabajo, se relacionó con que los trabajadores sanitarios planteaban que la mayoría de usuarios de los CAPS eran migrantes, pero que ellos no se daban cuenta de quién era migrante o procedente de otro país. En este sentido había un mecanismo de marcación y desmarcación por parte del personal de salud y un mecanismo de visibilización/invisibilización por parte de las migrantes, que admitían sus orígenes, pero negaban cualquier tipo de discriminación por ello. Estos mecanismos eran parte de las tensiones que se expresaban en las relaciones entre personal de salud y mujeres migrantes usuarias de CAPS. La atención y los cuidados de salud que se brindaban estaban permeados por ellas. En este artículo se abordará cómo las mujeres usuarias migrantes y el personal de CAPS conciben sus interacciones y la atención de salud en José C. Paz, y a partir de ello se buscará desentrañar la lógica (o lógicas) por la cual se marcan o desmarcan «diferencias» de nacionalidad. 


\section{Los procesos migratorios y la salud de las personas migrantes}

En el contexto mundial actual cada vez se desplazan más personas por diferentes motivos. Además, estos fenómenos adquieren características diversas de acuerdo con los múltiples factores - históricos, económicos, políticos, culturales - que intervienen en ellos, tanto en los países de procedencia como en los de migración/recepción. El tipo de análisis de estos procesos que ha predominado se ha enfocado en la perspectiva de los países receptores. En el caso de Argentina, la idea del «enclave europeo», de que descendemos de los barcos, se ha construido y reforzado desde estudios históricos y sociológicos. Según Grimson (2009), la sociología argentina, más que contrastar los imaginarios sociales de la época con la evidencia, hablaba por dichos imaginarios a la vez que contribuía a conformarlos. Ante la pregunta acerca del papel de las migraciones en la «modernización» de la Argentina, al pensarse eurocéntricamente, las migraciones limítrofes quedaban excluidas de dicho proceso, a pesar de que en los años sesenta la inmigración europea se había detenido y la regional continuó en su flujo constante.

La literatura producida en torno a los procesos migratorios ha contribuido a su legitimación (o no) y a las miradas que se construyeron sobre los «otros» migrantes, que, a su vez, repercuten en las personas migrantes. Las políticas migratorias reflejan (en parte) esas miradas y son las personas migrantes quienes reciben sus efectos.

La «movilidad» de población y el tipo de gestión migratoria gubernamental afectan a la salud y los derechos humanos tanto de los migrantes como de las personas a quienes dejan atrás. Con frecuencia, los migrantes se enfrentan a obstáculos para el desarrollo de su salud relacionados con la discriminación, el idioma y las barreras culturales, la condición jurídica y dificultades económicas y sociales. Al mismo tiempo, las políticas en materia de inmigración pueden tener consecuencias importantes para la salud pública (Hunt y Rodríguez Pizarro, 2003).

En Argentina, según los datos del último censo realizado en 2010, la población nacida en el extranjero llegó a 1.805 .957 personas, cifra que corresponde al 4,5\% de la población total. Según nacionalidad, quienes 
arribaron de Paraguay encabezan la población migrante: 550.713 personas, de las cuales 212.000 llegaron en el período 2002-2010. El 62,2\% de los nacidos en el extranjero reside en los partidos del Gran Buenos Aires y la Ciudad Autónoma de Buenos Aires.

Con respecto a las migraciones y su impacto en la salud, a nivel mundial, el acceso de los de migrantes y refugiados a los servicios de salud en los países receptores sigue siendo muy variable y no es abordado de forma coherente. Estas personas a menudo carecen de acceso a los servicios de atención sanitaria y están económicamente desprotegidas en esta materia (OMS, 2016). En el caso de Argentina, si bien la legislación nacional establece que toda persona inmigrante tiene derecho a gozar de las mismas condiciones de protección y amparo que las personas nativas, se necesitan investigaciones sociales que puedan iluminar los desafíos de desarrollar políticas públicas que logren concretar en la práctica los derechos garantizados por ley (Cerrutti et alii, 2010).

\subsection{Los estudios sobre migraciones y salud}

Dentro del campo de estudio de los procesos migratorios y salud, parte de la bibliografía consultada se ha centrado en la relación entre profesionales de salud y población migrante en España (Comelles, 2004; Meñaca, 2004; Moreno Preciado, 2008; Uribe, 2006; Rico Becerra, 2009), desde una perspectiva antropológica-etnográfica (Alonso, 2009; Allué, 2009; Antonín, 2009; Casadó, 2009; Castejón Bolea, 2009; Fuentes, 2009; Goldberg, 2009a; 2010). En un artículo de Martínez-Hernáez, Perdiguero Gil y Comelles (2015) sobre la genealogía de la antropología médica en España, los autores mencionan que el estudio de las migraciones se ha concentrado en numerosos aportes, desde el libro colectivo compilado por Comelles et alii (2010) hasta las tesis doctorales de Meñaca (2007), Bosch (2007), Rico (2009), Hurtado (2010) y Morales (2012). A su vez, refieren que el campo de la psiquiatría cultural y transcultural se revalorizó a partir del aumento de los flujos migratorios, favoreciendo trabajos sobre las concepciones populares sobre la salud y la enfermedad mental, los problemas de diagnóstico clínico, los culture-bound syndromes y los obstáculos a la comunicación clínica. Estos temas están representados en los estu- 
dios de González (2000) y Atxotegui (2000), en un estado de la cuestión realizado por Bernal y Comelles (2004), y en estudios antecesores como los de Obiols (1981; 1982), Obiols y Belloch (1987), Obiols et alii (1984) y Caballero (1996; 1997). Por último, Martínez-Hernáez, Perdiguero Gil y Comelles (2015) plantean que las investigaciones sobre migraciones y salud en España también tienen su origen desde la psiquiatría, con el informe de Cabaleiro en 1967 (1997), un artículo de Obiols y Belloch (1987), un libro colectivo publicado por psiquiatras (Tizón et alii, 1993) sobre las implicaciones clínicas de la presencia de una cada vez mayor diversidad cultural, y el estudio de caso realizado por Esteban y Díaz (1997), sobre las necesidades y prioridades en salud de inmigrantes extranjeros en el barrio de San Francisco de Bilbao.

El desarrollo de investigaciones en torno a migraciones se relacionó con que a finales del siglo xx España comenzó a ser receptor de un intenso flujo migratorio. Varios factores incidieron, entre ellos, el intenso dinamismo de la economía española, que significó un gran atractivo para la mano de obra extranjera y se tradujo en un fuerte crecimiento de la inmigración (Alonso y Blasco, 2007). Este fenómeno motivó una serie de pesquisas en el campo de la salud y la antropología que se han enfocado en la problemática de migraciones y atención de la salud, los cuidados culturales, interculturalidad y salud, y discriminación en el acceso a la atención de salud de la población migrante, entre otros temas.

La bibliografía especializada en Argentina sobre migraciones y salud (Cerrutti, 2006; Jelin, 2006; Jelin, Grimson y Zamberlin, 2006a; 2006b; Mombello, 2006; Caggiano, 2008; Goldberg, 2008; 2009b; Cerrutti et alii, 2010; Baeza, 2014.) coincide en señalar que la atención de esta población en las instituciones sanitarias está atravesada por miradas estereotipadas y distintas formas de discriminación, rechazo y violencia institucional (Pratto, 2016), a pesar de la existencia de una legislación que garantizaba el libre acceso ${ }^{2}$.

En general, se ha estudiado que las necesidades de salud de población migrante pueden diferir con respecto a las de habitantes de mayor antigüedad. A su vez, se han identificado obstáculos para poder recibir

2 La Ley 25.871, de Migraciones, de la República Argentina. 
atención sanitaria, como el elevado costo de los servicios en algunos países, las diferencias idiomáticas y culturales, la discriminación, las trabas administrativas, la imposibilidad de participar en planes de seguro médico locales, o la falta de información sobre los derechos en materia de atención sanitaria (OMS, 2016). Sumado a ellos, otro problema es que los sistemas nacionales de información sanitaria no desglosan sus datos de manera que se pueda realizar un análisis de los principales problemas de salud observados entre las poblaciones migrantes o provocados directamente por la migración (OMS, 2007) ${ }^{3}$.

Todas estas situaciones, vinculadas con los efectos de los desplazamientos poblacionales, convierten los procesos migratorios en un determinante social de la salud, en tanto que condicionan los procesos de salud-enfermedad-atención de las poblaciones migrantes.

\subsection{Las migraciones como determinantes de la salud}

Los determinantes sociales de la salud (DSS) son las circunstancias en que las personas nacen, crecen, viven, trabajan y envejecen. Los DSS son los responsables de las diferencias en los procesos de salud-enfermedad-atención (PSEA) de las poblaciones.

Esta perspectiva adquirió relevancia en los ochenta, cuando se publica el llamado Black Report (Townsend, Davidson, Whitehead, 1988), considerado el estudio pionero de las desigualdades sociales en salud. Este analizó la magnitud de las desigualdades en cuanto a mortalidad, morbilidad y uso del sistema sanitario, su evolución en el tiempo y las diferencias geográficas, y encontró que las clases más desfavorecidas, para todas las edades y sexos, tenían peores resultados en los indicadores de salud. Entre las recomendaciones del informe Black, se planteó la necesidad de mejorar las condiciones de vida de los grupos más desfavorecidos, y criterios para guiar las políticas sanitarias públicas, tales como que la asignación de los recursos se hiciera según criterios de necesidad (Sanjuán Núñez, 2015).

3 OMS, 2007. Salud de los migrantes. Informe de la secretaría. Consejo ejecutivo. EB122/11, 122. ${ }^{a}$ reunión, 20 de diciembre de 2007 , punto 4.8 del orden del día provisional. 
La importancia de este informe radicó en que puso de manifiesto que la distribución de la mortalidad, la discapacidad y la morbilidad varía de acuerdo con clases sociales, género, niveles de educación, ocupación, situación de empleo, etnia, situación migratoria o áreas geográficas de residencia. Es decir, puso en evidencia la debilidad científica de la ideología dominante, según la cual enfermar o morir prematuramente estaría condicionado principalmente por nuestra herencia genética, nuestros hábitos de salud libremente elegidos (no engordar, hacer ejercicio, beber con moderación, no fumar), el descubrimiento de una nueva tecnología médica o, incluso, como fruto del castigo divino o el azar (Segura del Pozo, 2013).

En el caso de las migraciones o desplazamientos poblacionales, repercuten de diversas maneras en los PSEA de migrantes. La exposición a un nuevo medio social y cultural, la separación de los seres queridos, la adaptación a un mundo de rasgos muchas veces desconocidos y los efectos del «duelo migratorio» (Atxotegui, 2000) pueden producir tensiones y desarreglos físicos y psíquicos.

Los migrantes recientes sufren considerablemente, en particular cuando provienen de sociedades pequeñas, homogéneas y rurales y deben adaptarse a grandes metrópolis, impersonales y socialmente heterogéneas (Cerrutti et alii, 2010). Si bien la autora se refiere a los migrantes bolivianos, las características de los procesos migratorios que describe y sus efectos sobre la salud pueden referenciarse a los grupos migrantes en general.

A su vez, presentan diversos estilos de vida y comportamientos que son interpretados desde el ámbito de la salud como elecciones individuales que los perjudican, por lo cual se les pide que los modifiquen. Sin embargo, la modificación de los estilos de vida de sujetos/grupos es más difícil por «condiciones estructurales de orden económico y también cultural que limitan o impiden la posibilidad de elección» (Menéndez, 1998: 50).

Otros factores que repercuten en la salud de las personas migrantes se relacionan con la mayor o menor distancia cultural respecto a la sociedad mayoritaria en destino, el sexo y la edad (Collazos et alii, 2014), así como la personalidad del individuo (García-Campayo y Sanz, 2002) y la accesi- 
bilidad a los servicios de salud (Bhugra, 2003). Además de las cuestiones relacionadas con el idioma y los estilos de comunicación, en la relación entre profesionales sanitarios y usuarios migrantes influirían también los estereotipos y prejuicios mutuos y las expectativas y experiencias previas, positivas o negativas de todos ellos. Situándonos en el actual contexto de la inmigración, es fácil comprender que los pacientes puedan sentir desconfianza o recelo hacia los profesionales: tanto ellos como el sistema sanitario en el que ejercen forman parte de la sociedad mayoritaria, una sociedad que a veces los rechaza, los explota y pretende expulsarlos (Sanjuán Núñez, 2015). Todos estos aspectos mencionados asociados a las migraciones repercuten en los PSEA de las mujeres migrantes con las que trabajamos.

\section{Metodología}

El presente trabajo fue realizado a partir de una investigación aprobada y financiada por la Universidad Nacional de José Clemente Paz (UNPAZ), ubicada en la provincia de Buenos Aires, Argentina. Presenta un carácter exploratorio de corte transversal y fue desarrollado desde un enfoque cualitativo. Se integró el análisis de fuentes secundarias (datos de INDEC y bibliografía específica, entre otras) con la producción de fuentes primarias (a partir de observación participante y entrevistas semiestructuradas a personal y usuarias migrantes del primer nivel de atención de la salud). En este sentido, las miradas y tensiones en torno a la nacionalidad de las usuarias, así como las marcaciones y desmarcaciones realizadas por las mujeres migrantes y el personal en la atención de salud, fueron analizadas en relación con los estudios sobre migraciones y salud desarrollados tanto en España como en Argentina. Esta articulación permitió hallar coincidencias con respecto a la discriminación, los problemas de comunicación y los prejuicios en el personal de salud, vinculados a la atención de la diversidad sociocultural, así como también especificidades con respecto a las marcaciones y desmarcaciones de nacionalidad efectuadas por las usuarias migrantes y el personal de los CAPS de José C. Paz. 
El tipo de abordaje cualitativo nos permitió recuperar la perspectiva de las personas involucradas, con base en entrevistas realizadas en tres centros de salud municipal.

En total se realizaron 23 entrevistas, 12 a usuarias migrantes y 11 a trabajadores de tres centros de atención primaria de la salud (CAPS), efectuadas durante febrero y marzo de 2019. Durante el trabajo de campo en los CAPS hallamos que las personas que concurrían en su mayoría eran mujeres, y en el caso de migrantes no observamos la presencia de varones. A su vez, en los días y horarios que hicimos las visitas domiciliarias a personas migrantes — de lunes a viernes de 9 a $15 \mathrm{~h}$-, los hombres integrantes del grupo doméstico se encontraban trabajando, por lo cual las entrevistas se realizaron a las mujeres migrantes que encontramos durante las recorridas y que quisieron participar de la investigación.

El primer acercamiento a los CAPS fue facilitado por una docente de la Universidad Nacional de José C. Paz (UNPAZ), enfermera y encargada de organizar la APS en el municipio. Ella intercedió para que uno de los secretarios $^{4}$ de salud nos autorizara la investigación en tres CAPS de la localidad. La selección de los CAPS se relacionó con la presencia de población migrante circundante y con criterios de acceso. Algunos CAPS se encuentran en zonas definidas por personal del municipio como «peligrosas» en cuanto a la inseguridad por robos y violencia. Otros se encuentran en zonas anegadas que presentan calles de tierra de dificultoso acceso. Y otros CAPS, además de estos inconvenientes, presentan poco personal y horarios restringidos. Por ello, desde la Secretaría de Salud municipal, nuestra informante nos recomendó los tres CAPS que consideramos para la investigación. Las entrevistas se realizaron, en el caso del personal de salud, en los CAPS, a veces en algún consultorio y otras en la administración o en la sala de espera. Por otro lado, las entrevistas a usuarias migrantes se desarrollaron en los CAPS (en la sala de espera o algún consultorio), en sus domicilios (dentro, en el comedor o patio, o fuera, en la entrada). Las entrevistas fueron realizadas por miembros del equipo de investigación, conformado por tres antropólogos y un enfermero. Cuando se entrevistó

4 La Secretaría de Salud está compuesta por una comisión directiva de salud conformada por el Dr. José Alberto Veglienzone (secretario firmante) junto con el Dr. Omar H. Vidable, Ricardo Denuchi y María Teresa Zamora. 
a usuarias migrantes, se abordaron sus procesos migratorios desde una perspectiva biográfica, indagando en torno a las motivaciones para migrar y aspectos en relación con su país de origen: la atención de la salud, los cuidados, sus itinerarios terapéuticos, los obstáculos o barreras en la atención, sus necesidades y demandas de salud, entre otros. Con respecto a su etapa actual, se repitieron los mismos ejes. En el caso de las entrevistas a personal de salud de los CAPS, se centraron en las experiencias de atención a personas migrantes, las interacciones en las consultas, sus prácticas de cuidado, las barreras u obstáculos y las necesidades y demandas que identifican en la atención a población migrante.

Todas las entrevistadas usuarias migrantes vinieron de Paraguay salvo una, que vino de Bolivia, y la mayoría tenía entre 25 y 45 años, salvo una, que tenía 64 años. La mayoría migró hace diez años. De los entrevistados trabajadores de salud de los CAPS, tres eran encargadas del CAPS, había tres enfermeros/as, dos promotoras de salud, dos médicos (clínico y pediatra) y un administrativo. El personal de salud tenía entre 40 y 50 años, salvo dos (un administrativo y un enfermero), que tenían más de 60 años. La mayoría trabajaba en estos CAPS desde hacía cinco años o tres (los que dependían del municipio han trabajado rotativamente en otros CAPS o en otros ámbitos municipales).

\section{José C. Paz, los CAPS y la población migrante}

José C. Paz es una localidad y, a la vez, cabecera del partido homónimo, en la provincia de Buenos Aires, Argentina. Está ubicada al noroeste del Gran Buenos Aires, a $40 \mathrm{~km}$ de la Ciudad de Buenos Aires. Posee una extensión de $50 \mathrm{~km}^{2}$ y un total de 216.637 habitantes.

Constituye un territorio que pasó de ser mayormente rural a zona periurbana industrializada, que sufrió los embates de las crisis político-económicas (la última en el año 2001), pero que, a pesar de ello, fue creciendo poblacionalmente a partir de la llegada de personas provenientes de distintas provincias y países que se asentaron en el territorio a partir de los diversos recursos y posibilidades que ofrecía, tanto económico-laborales como educativos, sanitarios y de terrenos. En diversos barrios de dicha localidad hay población procedente de otras provincias y de países sobre 
todo limítrofes. Existen en José C. Paz diversos barrios denominados Paraguayo, e incluso en el barrio La paz se ha conformado una comunidad guaraní, Kuarahy Öse Enteroitepeguara, reconocida por el INAI 5 .

De acuerdo con el censo del año 2010 realizado por el Instituto $\mathrm{Na-}$ cional de Estadísticas y Censos (INDEC), la población de José C. Paz que ha nacido en el extranjero proveniente de países limítrofes es de 11.558 personas; la de países de América no limítrofes es de 623 personas; la de Europa es de 1.219 personas; la de Asia es de 105 personas, y la de África es de 8 personas. Esta población se distribuye en barrios que presentan distintas situaciones de vulnerabilidad sociosanitaria, como la ausencia de red cloacal, agua de red o conexiones eléctricas seguras. En José C. Paz el porcentaje de hogares con al menos un indicador de necesidades básicas insatisfechas (NBI), que es utilizado para poder establecer una aproximación a las situaciones de pobreza estructural, alcanzaba en 2016 el 12\%, es decir, que existían 8.610 hogares en José C. Paz que presentaban al menos un indicador de NBI (ICO/UNGS, 2016).

La estructura sanitaria del municipio de José C. Paz cuenta con un hospital de dependencia provincial, el Mercante, y cuatro hospitales, dos centros de integración comunitaria (CIC) y veinte CAPS de dependencia municipal (ICO/UNGS, 2016). Si bien podría parecer suficiente, los efectores de salud de dependencia municipal presentan importantes faltas de recursos humanos y materiales, careciendo de insumos básicos. Por ello, las personas prefieren (cuando pueden solventar económicamente el viaje) acudir a hospitales de la capital federal para atender sus necesidades de salud.

Los CAPS que relevamos abren de lunes a viernes de 8 a 16 h y la mayoría ofrece atención básica (enfermería, clínica médica, pediatría, obstetricia, ginecología) y entrega medicación. Se ubican en diversos barrios del municipio que, a pesar de haberse conformado hace más de veinte años, presentan calles de tierra y escasa infraestructura de servicios básicos, como electricidad, gas, agua y cloacas, así como recolección de basura y limpieza de calles. Dos CAPS se encuentran próximos a basureros a cielo abierto y presentan terrenos descampados - algunos reciente-

5 Instituto Nacional de Asuntos Indígenas. 
mente ocupados-y problemas de seguridad, como robos en casas y en la calle. Uno de los CAPS, en el momento de inicio del trabajo de campo, en febrero de 2019, recién reabría sus instalaciones porque había estado en obras varios meses por reiterados robos que dejaron el edificio sin ventanas, puertas e insumos.

\subsection{Suposiciones, dudas y prejuicios en la atención de personas migrantes}

La población que concurre a los efectores, según el personal de salud entrevistado, es originaria de países limítrofes, mayormente de Paraguay, y en menor medida de Bolivia, Perú, Chile, provincias del nordeste del país (Misiones, Corrientes) y el conurbano bonaerense. En algunos CAPS se agregaron en los últimos años migrantes de Venezuela, China y África y miembros de la comunidad gitana.

Con respecto al registro de la nacionalidad, solo una enfermera mencionó que pregunta ese dato a los usuarios «por protocolo, porque lo tengo que llenar». La mayoría refiere que se da cuenta de que es «extranjera» cuando la persona posee un acento muy marcado o cuando anotan el documento en alguna ficha. Uno de los enfermeros dijo: «Yo no pregunto la nacionalidad, solo la fecha de nacimiento y el número de documento, en el documento, ahí te das cuenta de la nacionalidad, pero yo no les pongo la nacionalidad en la historia clínica». Una encargada de CAPS añadió: «Te das cuenta por el número de documento, 94, 93, 92, que no son de acá».

Cuando les solicitamos que nos contactaran con usuarios migrantes todos plantearon que no sabían ciertamente quién era migrante de sus usuarios más asiduos. Es decir, que, por un lado, señalaban que la mayoría de usuarios que se atendían en los CAPS eran paraguayos o de países limítrofes, pero en la atención de salud cotidiana no se daban cuenta ni prestaban atención a la nacionalidad/procedencia de usuarios.

Durante la entrevista realizada a la coordinadora-encargada de uno de los CAPS (en la cual también estuvieron presentes una de las administrativas y la enfermera, que de vez en cuando opinaban o intervenían con alguna acotación), dijo: 
[...] no sé cómo explicarte para que no quede mal, mucha gente que no tiene estudio, que vos le hablas y no entiende, hay que explicar las cosas varias veces [...], capaz que no estudiaron allá, ponele, en Paraguay, en el pueblo que estaría no estudiaría [...], hay gente que vos le explicas cosas y vos decís cómo se defienden porque no entienden, no entienden.

La enfermera agregó: «La población que llega son mamás adolescentes, con sus hijos, es gente humilde, sin preparación, viene del arrastre de los padres».

Salvo la promotora y el pediatra, el personal entrevistado de este CAPS coincidía en que desconocían si es que muchas usuarias tenían un problema de «retraso mental» o si eran así por «falta de educación». La coordinadora recordó: «Una paraguaya, que le habló Mónica [promotora] en paraguayo, en guaraní, tiene un retraso para mí. Tuvo el bebé y ella era un desastre con el bebé, vivía bajando de peso el bebé, le decíamos que viniera un día y venía cualquier día a cualquier hora y quería que la atendieran». La enfermera añadió más tarde: «La boliviana está embarazada otra vez, no entiende, trajo la ecografía que no se ve nada, solo el saco, porque tiene poco tiempo, pero no entendía, gente ignorante o tiene un retraso, no sé. Le dijimos que venga la semana que viene, va a venir cualquier día». A pesar de que nos aclaró que ella atendía a todos por igual, expresó (con respecto a los paraguayos):

[...] nosotros nos rompemos el alma para comprar la tierra, ellos vienen, se plantan ahí y encima tienen suerte y quedan. Después laburan por dos mangos, y se la pasan laburando, pero es todo gratis para ellos [...], usurpan tierras, trabajos, asignaciones familiares... Las embarazadas te cuentan que vienen a tener acá y vuelven cada tres o cuatro meses a cobrar [...], vienen al país a usar todas nuestras cosas [...], yo vivo cerca del CAPS y veo que las necesidades y demandas de salud son distintas porque el paraguayo quiere todo o te exige todo, más que el argentino.

Sin embargo, tanto la promotora de salud como el pediatra de ese CAPS manifestaron que «las necesidades son las mismas, un niño necesita atención si está enfermo, y necesita una atención si es niño sano, un control, las vacunas. Si me preguntás, no sé si es de acá o de otro país, y sus madres tampoco, sí que en su mayoría el barrio es paraguayo». 
En otro de los CAPS se reproducían estas suposiciones, dudas y prejuicios acerca de las personas migrantes que atendían. Allí fue posible identificar a usuarias migrantes para entrevistar porque el ginecólogo nos trajo una lista con nombres y documentos de las pacientes que iba a atender y nos dijo que viésemos quién era «paraguaya o boliviana». Había una fila de mujeres sentadas en la sala de espera a las que les dijo con un tono autoritario que les iban a hacer una entrevista. Les aclaramos que no era obligatorio y les leímos el consentimiento informado. Luego las entrevistamos en el consultorio de al lado. Después de unos días nos enteramos que el ginecólogo no había atendido a una mujer que entrevistamos porque cuando la llamó estaba en la entrevista y, aunque después ella lo esperó hasta la última paciente, él no la quiso atender y se fue.

Al menos cuatro trabajadores de salud mencionaron la necesidad de arancelar la atención y los estudios para migrantes extranjeros, para «guardar para los de acá» debido a la crisis y el ajuste económico que restringe los insumos y recursos en salud.

Estos relatos y prácticas reproducían discursos que cuestionan la legitimidad de las migraciones y migrantes de países limítrofes, y reflejaban la relación entre los argentinos y los limítrofes como exclusivamente mediada por el prejuicio y la discriminación, donde ser «boliviano», «paraguayo» o «chileno» implica necesariamente encarnar un estigma o ser marginado (Trpin y Vargas, 2004). Pero en el trabajo de campo también relevamos situaciones y prácticas que planteaban otra mirada acerca de las personas migrantes, más empática, e incluso evidenciaban una valoración positiva de las usuarias migrantes.

Una promotora de salud refirió:

[...] escucho a menudo que la gente dice que los paraguayos chupan ${ }^{6} \mathrm{y}$ les pegan a las mujeres, que son violentos cuando toman, pero acá son violentos y no trabajan, no mantienen la casa, son más vagos [...+], los vecinos argentinos se quejan a veces de los paraguayos, escucho «estos paraguayos de mierda», pero las mujeres son retrabajadoras, van a la consulta, vacunan a los hijos, mejor que las argentinas..., voy a parecer que hablo en contra de los argentinos pero vos ves las casas de los para-

6Chupar significa consumir bebidas alcohólicas. 
guayos [...], vas a sus casas, y yo no aviso, y dos veces que fui a ver a una señora estaba baldeando, limpian, son higiénicos, más que los argentinos, te escuchan y respetan.

En este sentido, uno de los médicos manifestó: «Las mujeres paraguayas no las veo sometidas, maduran demasiado rápido, las hijas son las que manejan la salud, las que hablan, llevan a sus padres, a sus madres, y a sus hijos [...], se preocupan por la salud, confían en los médicos de acá, les encanta hacerse estudios, me dicen "pídame todo"».

Todo el personal de salud coincidía en que en los barrios «te das cuenta quién es paraguayo por la casa, si es de material es de paraguayos, si es un rancho es de argentinos seguro».

Si bien coexistían diversas miradas acerca de las personas migrantes por parte del personal de salud de los CAPS, lo que parecía compartirse era la idea de que «los paraguayos» eran «trabajadores» y hacían sus «casas» (así hubieran ocupado el terreno), a diferencia de los «argentinos». Estas diferencias evidentes en los barrios parecían desdibujarse en los CAPS.

En la atención de salud en los CAPS observamos un doble mecanismo de marcación-desmarcación por parte del personal de salud. Por un lado, señalaban que los usuarios eran en gran medida migrantes extranjeros. Por otro lado, aducían no reconocer cuando un usuario era migrante, ya que no le preguntaban su nacionalidad en general, aunque en algún momento podían solicitarle el documento de identidad y por el número darse cuenta; sin embargo, esta práctica no era obligatoria ni habitual. Con excepción del ginecólogo (al que no pudimos entrevistar) y una enfermera, que sí registraban este dato, el resto no lo consignaba.

El personal de los CAPS en su mayoría no relacionaba los problemas de salud con una población específica. Señalaban que había patologías estacionales más frecuentes y que las condiciones económicas incidían también. Algunos encargados, promotoras y médicos mencionaron la contaminación del agua y de la tierra, los basureros a cielo abierto, y la violencia de género, los embarazos adolescentes, y las enfermedades de transmisión sexual, entre otros, en los barrios que según ellos eran en su mayoría «asentamientos paraguayos», pero no identificaban a sus 
«pacientes» por nacionalidad. La condición migrante no era identificada como un determinante de los PSEA de las usuarias. Esta falta de correlación, en parte debida a la hegemonía de la perspectiva biologicista en la formación de los profesionales, evidenciaba un desconocimiento de información que podría facilitar las prácticas sanitarias y la salud de las personas migrantes. La marcación o referencia a la nacionalidad de usuarios migrantes por parte del personal de los CAPS en general aparecía asociada a prejuicios y/o diversos estereotipos que podían resaltar características/cualidades "positivas», como la capacidad de trabajo, los hábitos de limpieza e higiene, la responsabilidad en los cuidados de salud; o «negativas», como la capacidad de usurpar tierras, de robar el trabajo a los argentinos, y la falta de educación, entre otros aspectos ya mencionados.

A su vez, por parte de las usuarias migrantes también observamos un doble mecanismo de visibilización-invisibilización de su adscripción nacional.

\subsection{Activación y desactivación de la nacionalidad en usuarias migrantes}

En las entrevistas pudimos reconstruir los procesos migratorios de las usuarias migrantes de los CAPS. Todas se movilizaron hacia Argentina hace aproximadamente más de diez años (migraciones recientes), contando en el lugar de recepción con algún familiar o persona cercana que les facilitó la llegada. Si bien todas comenzaron a trabajar en ese momento, actualmente ocho de las doce son amas de casa. Todas tienen hijos y viven en José C. Paz, cerca de los CAPS, y completaron el nivel primario de educación (menos una), y muchas también el secundario. Si bien cinco dijeron que migraron por trabajo o por cuestiones relacionadas con él, casi ninguna respondió claramente con los motivos de migración. $\mathrm{Mu}$ chas mencionaron que vinieron «de paseo» a lo de un familiar o conocido y se quedaron. Esto les facilitó la «adaptación» en el nuevo lugar de vida. Actualmente se encuentran en pareja con hombres de su misma nacionalidad, salvo una que está separada. Sus maridos trabajan mayormente en la construcción, fábricas, y plomería, realizan trabajos de pintura, jardinería, y «chambean» (trabajos temporarios de corta duración). Sus 
hijos han nacido en Argentina y algunas han tenido anteriormente hijos en Paraguay; algunos permanecen allí. Dos mujeres envían dinero para los cuidados de familiares (padre e hijos) en Paraguay. Todas las migrantes paraguayas hablan en guaraní con connacionales y con sus familiares. No suelen enseñarles el idioma guaraní a sus hijos, pero expresaron que quisieran que al menos entiendan, y muchos al ir de visita a Paraguay «escuchan y entienden, pero responden y hablan en español». En Argentina se reúnen con sus parientes y realizan comidas típicas paraguayas en determinadas fechas (Semana Santa, Día de la Madre en Paraguay, entre otras). Si bien todas vuelven a Paraguay (o Bolivia) de «visita» para ver a sus familiares en las vacaciones, la mayoría refiere que si las condiciones fueran distintas preferirían vivir allá porque «es más tranquilo», pero acá ya tienen sus casas y su familia, por lo que no piensan volver a vivir allá.

En sus historias estas mujeres migrantes no parecían mostrar una directa integración cultural/nacional, ni una asimilación cultural, pudimos observar, tal como plantea Trpin (2004), que los modos en los que las personas migrantes cotidianamente refuerzan su opción por estar fuera del país de origen son diversos y que su permanencia en el país receptor se justifica y negocia cotidianamente generando diferentes modos de «ser extranjeros».

En esas negociaciones entran en juego activaciones y desactivaciones de la nacionalidad. En sus casas hablan guaraní, toman mate o tereré con yuyos, festejan determinadas fechas con comidas típicas, e incluso cultivan sus plantas y yuyos medicinales que tenían en Paraguay. En otros contextos extradomiciliares, como los CAPS, no hablan su idioma, ni comentan determinadas prácticas de salud, como el consumo de yuyos medicinales, ni mencionan su nacionalidad salvo que les pregunten. Tal como plantean Trpin y Vargas (2004), es importante observar cuándo y por qué son activados los límites étnicos. La adscripción étnico-nacional de familias migrantes puede analizarse como un recurso que es activado en determinados contextos. Durante la atención de salud en los CAPS y otros efectores de salud, parece mejor que pase «desapercibida» la adscripción nacional, así como también en los denominados contextos barriales en los que circulan y se reproducen discursos y prácticas discriminadores, que, a su vez, son negados por las usuarias migrantes. 
La mayoría refirió no haber sido discriminada en el país en ningún momento: «Nunca me discriminaron» (Beatriz), «Nunca me trataron mal por ser paraguaya» (María), «A mí me trataron mal cuando me fui a dar la vacuna, la enfermera era antipática pero para mí es su carácter, no es porque sea paraguaya» (Rosa), «Nunca escuché a nadie que lo discriminaran» (Juana). Una sola (Ramona) mencionó que en algunos trabajos que realizó (de limpieza en hogar de ancianos y empleada doméstica en casa particular) sus patronas la maltrataron y le dijeron «paraguaya de mierda». Sin embargo, estos maltratos los exponía como una excepción, y le costó recordarlos.

Las mujeres migrantes referían con respecto a la atención de salud en los CAPS: «No tenemos nada que recriminar», «Acá la salud es gratuita y en Paraguay no», «En el CAPS no tenemos quejas, nos atienden cuando vamos», "Cuando necesito que me atiendan voy, saco turno, no tengo problemas», «No tengo quejas», «Acá en la salita me atienden bien, a pesar de que se cae a pedazos, tiene al mejor pediatra».

Las usuarias migrantes, por otra parte, negaban que su nacionalidad pudiera ser causa de discriminación. En determinados contextos su nacionalidad aparecía desactivada, como si la diferencia no existiera, no importara o no condicionara comportamientos. Sus relatos acerca de que nunca escucharon que nadie fuera discriminado por ser paraguayo se enmarcaban en esos contextos en los cuales era mejor pasar desapercibido. En un contexto nacional que los «recibió» y les permitió trabajar, construir «su familia», «su casa», todas valoraban y agradecían las posibilidades de crecimiento que encontraron en el país. A pesar de que los barrios «paraguayos» presentaban condiciones de vida deficitarias que ellas mismas mencionaban como generadoras de problemas de salud (determinantes de la salud), como no tener gas, agua de red, la basura sin recolección, el peligro de un canal de varios metros de profundidad abierto sin protección, los perros sueltos, las calles de tierra inundables, entre otros, en comparación con las oportunidades y realidades que vivían en sus países de origen, las expectativas de vida en los países «receptores» resultaban satisfechas en gran medida. En referencia a sus logros en Argentina expresaron: «No extraño nada, trabajo y me siento bien, tran- 
quila [se quedó en silencio y se le pusieron los ojos llorosos], se extraña la familia. Las costumbres..., acá casi todos son paraguayos así que las costumbres no se extrañan, acá tengo mi casita» (María), «La felicidad es que tenemos la casa» (Rosa).

\section{Conclusiones}

A lo largo de este trabajo describimos las características sociodemográficas del territorio de José C. Paz, poniendo especial atención en la población migrante y su relación con el sistema público de salud local. Nos centramos en las miradas y tensiones en torno a la nacionalidad de usuarias migrantes y trabajadores de salud de tres CAPS de dicha localidad. A partir de la observación y entrevistas en profundidad, indagamos en algunos factores generales y específicos que afectan la salud y la vida de los colectivos de migrantes en este escenario. Hemos podido relevar problemáticas de salud que se perciben desde las usuarias migrantes de Paraguay y las percibidas por el personal de salud de los CAPS.

En este sentido, reconocimos algunas coincidencias y diferencias: por un lado, la mirada del personal de salud se enfocaba sobre todo en patologías estacionales, no reconociendo la condición migrante como un factor que afecta la salud, y, por otro, las usuarias vinculaban los problemas de salud con las condiciones de vida.

Con respecto a la atención, observamos que se encontraba condicionada por la mirada del personal de salud sobre la falta de educación de las usuarias migrantes, por los prejuicios acerca de que eran «usurpadoras» $\mathrm{y}$ «vienen al país a usar todas nuestras cosas», por miradas que reproducían estereotipos estigmatizantes que coexistían con otras percepciones y/o estereotipos acerca de las mujeres migrantes que remarcaban su capacidad de trabajo, de cuidados, de higiene y de responsabilidad. En un país como Argentina, las desigualdades sociales y la pobreza han constituido el escenario que condicionó y abonó las miradas y tensiones en torno a la nacionalidad de personas migrantes. Las miradas con respecto a los migrantes que circulaban en el personal de salud de José C. Paz (que también padece situaciones socioeconómicas desventajosas) fueron permeadas por dicho contexto de desigualdad, que, a su vez, condicio- 
naba las miradas de las usuarias que parecían no percibir situaciones de discriminación y/o no asociarlas con su nacionalidad. Las tensiones cotidianas que producían el ajuste económico, la escasez de trabajo y de recursos e insumos, también repercutían (en general) negativamente en los imaginarios sobre personas migrantes que poseía el personal de salud. Eran esas mismas tensiones las que intentaban minimizar las usuarias migrantes a través de la desmarcación y minimización o negación de la discriminación. Para estas mujeres, fuera de sus casas, en los CAPS, la nacionalidad que podría conllevar discriminación y estigma, en ese contexto, parecía desactivada en sus relatos: «Nunca fui discriminada», «No tengo quejas» (en relación con la atención y el trato). Invisibilizaban su nacionalidad de manera efectiva ya que gran parte del personal de salud dudaba acerca de qué usuaria era o no migrante.

Observamos que las posibilidades de afirmación de una identidad dependían de la probabilidad real de tal afirmación, es decir, del conjunto de las relaciones que definían su contexto (Trpin y Vargas, 2004). En determinados contextos convenía desdibujar los límites étnico-nacionales para lograr determinados objetivos, como la atención sanitaria sin posibles obstáculos, como podrían ser la negación de la atención, el rechazo, la discriminación o maltratos.

A partir de nuestro análisis vimos que la adscripción nacional puede entenderse como una identidad potencial que puede ser tomada y movilizada cuando resulta conveniente a los propósitos de un encuentro particular (Wallman, 1979, en Vargas, 2005), como puede ser una consulta de salud. Los usos de la nacionalidad, en países sudamericanos, en los cuales la diferencia nacional no se denota (como sí ocurre en España, sobre todo con la inmigración africana), sino que se «comprueba»y «controla» en los documentos, puede entonces ser ocultada, tergiversada o transformada en función del contexto (Goffman, 1959; Barth, 1969, en Vargas, 2005). Pudimos observar que estas usuarias paraguayas, según los contextos, ocultaban, solapaban o reivindicaban su nacionalidad (en los CAPS, en los barrios y en los ámbitos domésticos). La marcación y desmarcación realizada por usuarias migrantes estaba relacionada con las posibilidades de acceso a recursos necesarios para sus condiciones ma- 
teriales de existencia. Por último, nos parece importante señalar que los mecanismos de negación de la discriminación por la procedencia nacional descritos pueden ayudar a las mujeres migrantes a construir y recrear escenarios de vida impensados, lejos de sus países de origen, pero donde refieren «la felicidad es que tenemos la casa».

\section{Bibliografía}

Allué, X. (2009). «Norteafricanos en áreas rurales del centro de España». En J. Comelles, X. Allué, M. Bernal, J. Fernández Rufete y L. MascareLLA (comps.). Migraciones y salud (pp. 374-389). Tarragona: Publicacions URV.

Alonso, M. (2009). «Mujeres inmigrantes marroquíes en el sistema de salud catalán». En J. Comelles, X. Allué, M. Bernal, J. Fernández Rufete y L. Mascarella (comps.). Migraciones y salud (pp. 358-373). Tarragona: Publicacions URV.

Alonso, M. y Blasco, E. F. (2007). España: de la emigración a la inmigración. Archives Ouvertes. Fr.

Atxotegui, J. (2000). «Los duelos de la migración: una aproximación psicopatológica y psicosocial». En E. Perdiguero y J. Comelles (comps.). Medicina y cultura. Estudios sobre la antropología y la medicina. Barcelona: Bellaterra.

BAEZA, B. (2014). «La memoria migrante y la escucha de los silencios en la experiencia del parto en mujeres migrantes bolivianas en Comodoro Rivadavia (Chubut, Argentina)». Anuario Americanista Europeo, (11), 179197.

Bhugra, D. (2003). «Migration and depression». Acta Psychiatrica Scandinavica, 108 (supl. 418), 67-72.

CASADÓ, L. (2009). «Sobre la construcción cultural de las emociones: Los malestares de las mujeres inmigrantes marroquíes de un municipio rural en Cataluña». En J. Comelles, X. Allué, M. Bernal, J. Fernández Rufete y L. Mascarella (comps.). Migraciones y salud (pp. 405-420). Tarragona: Publicacions URV.

CAgGiano, S. (2008). «Racismo, fundamentalismo cultural y restricción de la ciudadanía: formas de regulación social frente a inmigrantes en 
Argentina». En S. Novick (comp.). Las migraciones en América Latina (pp. 31-51). Buenos Aires: Catálogos.

CAstejón Bolea, R. (2009). «La atención primaria de la salud ante la inmigración». En J. Comelles, X. Allué, M. Bernal, J. Fernández Rufete y L. Mascarella (comps.). Migraciones y salud (pp. 207-221). Tarragona: Publicacions URV.

Castiglione, M. C. (2004). «Inmigrantes limítrofes y organizaciones intermedias: una experiencia en el barrio de la boca». VI Jornadas de Sociología. Facultad de Ciencias Sociales, Universidad de Buenos Aires, Buenos Aires.

Cerrutti, M. (2006). «Problemas de salud, utilización de servicios y conductas preventivas de los migrantes limítrofes en la Argentina». En E. JeLIN (dir.). Salud y migración regional. Ciudadanía, discriminación y comunicación intercultural (pp. 15-32). Buenos Aires: Ides.

Cerrutti, M., Mombello, L. y Caggiano, S. (2010). Salud y migración internacional: mujeres bolivianas en la Argentina. UNFPA.

Collazos, F. et alii (2014). «Salud mental de la población inmigrante en España». Revista Española de Salud Pública, 88 (6), 755-761.

ComelLes, J. (2004). «El regreso de las culturas: diversidad cultural y práctica médica en el siglo xxI». En G. Fernández (comp.). Salud e Interculturalidad en América Latina. Perspectivas antropológicas (pp. 7-30). Quito: Abya Yala.

Fuentes, J. M. (2009). «Políticas sanitarias y población inmigrante. Los casos del Reino Unido, Francia y España». En J. Comelles, X. Allué, M. Bernal, J. Fernández Rufete y L. Mascarella (comps.). Migraciones y salud (pp. 108-132). Tarragona: Publicacions URV.

García-CAmpayo, J. y SAnz, C. (2002). «Salud mental en inmigrantes: el nuevo desafío». Medicina Clínica (Barcelona), 118 (5), 187-191.

GolDBERG, A. (2008). «Etnografía de los procesos de salud/enfermedad/ atención en inmigrantes bolivianos del Área Metropolitana de Buenos Aires». IX Congreso Argentino de Antropología Social. Universidad Nacional de Misiones, Posadas.

- (2009a). «Fábricas de padecimientos. La salud laboral de los inmigrantes en los invernaderos del poniente almeriense». En J. Comelles, X. 
Allué, M. Bernal, J. Fernández Rufete y L. Mascarella (comps.). Migraciones y salud (pp. 442-448). Tarragona: Publicacions URV.

— (2009b). «Salud e interculturalidad: aportes de la Antropología Médica para el abordaje sociosanitario de la población boliviana de la Ciudad Autónoma de Buenos Aires». Temas de patrimonio cultural, (24), 233-245.

- (2010). «Exploración antropológica sobre la salud/enfermedad/atención en migrantes senegaleses de Barcelona». Cuicuilco, 17 (49), 139-156. Grimson, A. (2009). «Prólogo». En G. HALPERn. Etnicidad, inmigración y política. Representaciones y cultura política de exiliados paraguayos en Argentina (pp. I-VI). Buenos Aires: Prometeo Libros.

Hunt, P. y Rodríguez Pizarro, G. (2003). Migración internacional, salud y derechos humanos. Ginebra: OMS.

Instituto del Conurbano (ICO)/Universidad Nacional de General Sarmiento (UNGS) (2016). Datos socio-sanitarios, Partido de José C. Paz. Instituto del Conurbano, Área de Política Social-Diseño y Gestión de Políticas de Salud. UNGS.

Instituto Nacional de Estadísticas y Censos (INDEC) (2010). Censo Nacional de Población, Hogares y Vivienda 2010.

JELIN, E. (2006). «Introducción». En E. JELIN (dir.). Salud y migración regional. Ciudadanía, discriminación y comunicación intercultural (pp. 7-13). Buenos Aires: Ides.

Jelin, E., Grimson, A. y Zamberlin, N. (2006a). «¿Servicio? ¿Derecho? ¿Amenaza? La llegada de inmigrantes de países limítrofes a los servicios públicos de salud». En E. JeLIN (dir.). Salud y migración regional. Ciudadanía, discriminación y comunicación intercultural (pp. 33-46). Buenos Aires: Ides.

Jelin, E., Grimson, A. y Zamberlin, N. (2006b). «Los pacientes extranjeros en la mira». En E. JeLIN (dir.). Saludy migración regional. Ciudadanía, discriminación y comunicación intercultural (pp. 47-55). Buenos Aires: Ides.

MenéndeZ, E. L. (1998). «Estilos de vida, riegos y construcción social. Conceptos similares y significados diferentes». Estudios Sociológicos, (46), 37-67. 
Menéndez, E L. (2004). «Modelos de atención de los padecimientos: de exclusiones teóricas y articulaciones prácticas». En H. SPINELli (comp.). Salud colectiva. Buenos Aires: Lugar.

MeÑACA, A. (2004). «Salud y migraciones: sobre algunos enfoques en uso y otros por utilizar». En G. FERNÁNDEZ (comp.). Salud e interculturalidad en América Latina. Perspectivas antropológicas (pp. 53-64). Quito: Abya Yala. MombelLo, L. (2006). «El acceso a la salud de los inmigrantes limítrofes en el Alto Valle de Río Negro y Neuquén». En E. Jelin (dir.). Salud y migración regional. Ciudadanía, discriminación y comunicación intercultural (pp. 91-102). Buenos Aires: Ides.

Moreno Preciado, M. (2008). «Las implicancias familiares en los cuidados de los inmigrantes». Cultura de los Cuidados, año XII (24), 59-65.

Organización Mundial de la Salud (OMS) (2007). Salud de los migrantes. Informe de la Secretaría. Consejo ejecutivo. $122 .^{a}$ reunión, punto $4.8 \mathrm{del}$ orden del día provisional. Washington: OMS.

- (2016). Promoción de la salud de los migrantes. Consejo Ejecutivo. 140. ${ }^{\text {a re- }}$ unión, punto 8.7 del orden del día provisional. Washington: OMS.

PRATTO, L. (2016). La precariedad de la vida. Mujeres bolivianas y tuberculosis en el sur de la ciudad de Buenos Aires (tesis de maestría, Ms. Ides).

Rico BECERRA, J. I. (2009). El inmigrante «enfermo»: apuntes y reflexiones desde un trabajo antropológico. Murcia: Isabor.

SANJUÁN NúÑEZ, L. (2015). Antropología, epidemiología y asistencia sanitaria. Propuestas para el estudio interdisciplinar de las desigualdades sociales en salud y la inmigración (tesis de doctorado, Ms. Departament d'Antropologia Social i Cultural Universitat Autònoma de Barcelona).

Segura del Pozo, J. (2013). Desigualdades sociales en salud: conceptos, estudios e intervenciones (1980-2010). Doctorado en Salud Pública. Ediciones para la Universidad Nacional de Colombia, Bogotá.

Townsend, P., Davidson, N. y Whitehead, M. (1988). Inequalities in health: The Black Report. London: Pelican Books.

TRpIN, V. (2004). Aprender a ser chilenos. Identidad, trabajo y residencia de migrantes en el Alto Valle de Río negro. Buenos Aires: Antropofagia. 
TrPin, V. y VARGAS, P. (2004). «Migrantes y trabajadores en la Argentina: la etnicidad como recurso». VI Jornadas de Sociología. Facultad de Ciencias Sociales, Universidad de Buenos Aires, Buenos Aires.

URibe, J. M. (2006). «Migraciones y salud - Préstamos de ida y vuelta». En G. FERnÁNdeZ (comp.). Salud e interculturalidad en América Latina. Antropología de la salud y crítica intercultural (pp. 83-92). Quito: Abya Yala.

VARGAS, P. (2005). Bolivianos, paraguayos y argentinos en la obra. Identidades étnico-nacionales entre los trabajadores de la construcción. Buenos Aires: Antropofagia. 